\title{
ROLE OF FINE NEEDLE ASPIRATION CYTOLOGY IN BREAST LESIONS
}

\author{
Atul Upadhyay', Surubhi Solanki², Sarandeep Singh Puri ${ }^{3}$, Paramjit Singh Dhot ${ }^{4}$, Parul Singhal ${ }^{5}$ \\ 13rd Year Postgraduate Student, Department of Pathology, SIMS, Hapur, Uttar Pradesh. \\ 2Tutor, Department of Pathology, SIMS, Hapur, Uttar Pradesh. \\ ${ }^{3}$ Assistant Professor, Department of Pathology, SIMS, Hapur, Uttar Pradesh. \\ 4 Professor and HOD, Department of Pathology, SIMS, Hapur, Uttar Pradesh. \\ 5 Professor, Department of Pathology, SIMS, Hapur, Uttar Pradesh.
}

ABSTRACT
BACKGROUND
FNAC is a relatively simple procedure with good patient acceptance and low morbidity. It is an accurate, safe and
procedure in the diagnosis of various breast lesions- both malignant and non-malignant.
Aims and Objectives:
1. To study the spectrum of both benign and malignant lesions of breast by FNAC.
2. To study the cytomorphological features of various breast lesions by FNAC.
3. To study the incidence of various breast lesions and categorisation of breast lesions on the basis of five tier system.

\section{MATERIALS AND METHODS}

The study was a descriptive cross-sectional study carried out from July 2016 to June 2017 in Department of Pathology, Saraswathi Institute of Medical Sciences, Anwarpur, Pilkhuwa, Hapur, U. P. The inclusion criterion included all the new cases of palpable breast mass sent for FNAC to the Pathology department including both males and females Fine Needle Aspiration Cytology (FNAC) was performed on enrolled patients by the Pathologist. The staining methods used were- Giemsa Staining and Haematoxylin and Eosin Staining.

\section{RESULTS}

The most common affected age group was 21 to 40 years having $60 \%$ patients. FNAC results were divided according to the spectrum of lesions on cytomorphological interpretation and diagnosis into benign (61 cases), inflammatory (22 cases) and malignant (12 cases), atypical/ probably benign ( 3 cases) and no definite opinion (2 cases). In 12 malignant lesions, maximum cases that is 10 cases were of ductal carcinoma and only 2 were diagnosed as mucinous carcinoma. Categorisation of breast lesion on the basis of 5 tier system was done in which 2 cases were of C1, 65 cases of C2, 18 cases of C3, 3 cases of C4 and 12 cases of C5.

\section{CONCLUSION}

It can be concluded that FNA should be used as a routine diagnostic procedure for breast lumps due to its cost effectiveness, quick results and high accuracy.

\section{KEY WORDS}

FNAC, Breast, Benign, Malignant.

HOW TO CITE THIS ARTICLE: Upadhyay A, Solanki S, Puri SS, et al. Role of fine needle aspiration cytology in breast lesions. J. Evolution Med. Dent. Sci. 2018;7(21):2546-2549, DOI: 10.14260/jemds/2018/573

\section{BACKGROUND}

Breast is a dynamic organ which undergoes cyclical changes under the influence of hormone and growth factors acting on the epithelial and stromal tissue throughout the reproductive life of a woman. ${ }^{1}$ Various breast lesion are common in females with a wide range of variability from inflammatory lesions, benign and malignant breast lesions. ${ }^{2}$ Breast lumps are common complaints of women visiting health organisation clinics, of which 80 to $85 \%$ are benign and rest are malignant. . $^{-5}$ Breast cancer is the leading cause of morbidity and mortality in women. ${ }^{6}$ By 2020 breast cancer is set to overtake cervical cancer as the most common type of cancer among all women in India. ${ }^{7}$

'Financial or Other Competing Interest': None.

Submission 20-03-2018, Peer Review 18-04-2018,

Acceptance 25-04-2018, Published 21-05-2018.

Corresponding Author:

Dr. Sarandeep Singh Puri,

R-12/72, Raj Nagar,

Ghazabad-201001, Uttar Pradesh.

E-mail: drsarandeep147@gmail.com

DOI: $10.14260 /$ jemds $/ 2018 / 573$
Fine needle aspiration cytology has become widely accepted as simple and cost effective diagnostic tool with high sensitivity and specificity. ${ }^{8}$

The sensitivity and specificity of Fine needle aspiration cytology (FNAC) as a diagnostic tool for palpable breast lumps are $65-99 \%$ and 96 - 100\% respectively. ${ }^{9}$ Fine needle aspiration cytology (FNAC) is widely accepted as a reliable technique in the initial evaluation of palpable and nonpalpable (guided biopsy) breast lumps. The procedure is simple, safe, cost effective, minimally invasive, rapid and as sensitive as biopsy. ${ }^{10}$ This study was conducted to study the spectrum of both benign and malignant lesions of breast, to study the cytomorphological features of various breast lesions by FNAC, to see the incidence and categorisation of lesion on basis of five tier system.

\section{Aims and Objectives}

1. To study the spectrum of both benign and malignant lesions of breast by FNAC.

2. To study the cytomorphological features of various breast lesions by FNAC.

3. To study the incidence of various breast lesions. 
4. Categorisation of breast lesion on basis of five tier system.

\section{MATERIALS AND METHODS}

Study Design- A cross-sectional study.

Study Period - July 2016 to June 2017.

\section{Study Place}

Department of Pathology, Saraswathi Institute of Medical Sciences, Anwarpur, Pilkhuwa, Hapur, U. P.

\section{Study Population}

100 cases.

\section{Inclusion Criteria}

1. All the new cases of palpable breast mass sent for FNAC to the pathology department.

2. Includes both males and females.

\section{Sample Size}

Patients fulfilling all inclusion and exclusion criteria were enrolled in the study. A written informed consent was obtained from all the subjects before their enrolment in study.

A detailed clinical history was taken with special reference to menstrual age at marriage, age at first delivery, parity and habit of breast feeding, pain in breast and discharge from nipple. An inquiry was made regarding the use of oral contraceptive, dietary history, history of injury and radiation to the breast region and family history of tumours. A complete local and general examination including size of the breast and size of the lump. Consistency of lump, tenderness, fluctuation in the lump, fixity of the lump to skin or chest wall, any previous operative mark, any ulcerated area over the skin of breast and the presence of axillary lymph nodes was carried out in all 100 patients.

Fine needle aspiration cytology (FNAC) was performed on enrolled patients by the Pathologist. The staining methods used were Giemsa Stain, Haematoxylin and Eosin stain.

\section{Statistical Analysis}

All data was collected and verified. Collected data was subjected to SPSS (version 20) for analysis. Results were statistically evaluated by applying Chi-square test. $\mathrm{P}$ value of 0.05 was considered significant.

\section{RESULTS}

The most common affected age group was 21 to 40 years having $60 \%$ patients. FNAC results were divided according to the spectrum of lesions on cytomorphological interpretation and diagnosis into benign (61 cases), inflammatory (22 cases) and malignant (12 cases), atypical/ probably benign ( 3 cases) and no definite opinion ( 2 cases). In 12 malignant lesions maximum cases, that is 10 cases were of ductal carcinoma and only 2 were diagnosed as mucinous carcinoma. Categorisation of breast lesion on the basis of 5 tier system was done in which 2 cases were of $\mathrm{C} 1,65$ cases of $\mathrm{C} 2,18$ cases of $\mathrm{C} 3,3$ cases of $\mathrm{C} 4$ and 12 cases of $\mathrm{C} 5$.

\begin{tabular}{|c|c|c|}
\hline Gender & Frequency & Percent \\
\hline Female & 91 & 91.0 \\
\hline Male & 9 & 9.0 \\
\hline Total & $\mathbf{1 0 0}$ & $\mathbf{1 0 0 . 0}$ \\
\hline \multicolumn{2}{|c|}{ Table 1. Gender distribution of Patients } \\
\hline
\end{tabular}

Out of 100 patients, 9 were males and 91 were females.

\begin{tabular}{|c|c|c|}
\hline Type of Lesions & Frequency & $\mathbf{\%}$ \\
\hline Benign epithelial hyperplasia & 17 & 17.0 \\
\hline Benign fibroadenoma & 31 & 31.0 \\
\hline Benign fibrocystic lesion & 9 & 9.0 \\
\hline Benign gynaecomastia & 4 & 4.0 \\
\hline Inflammatory acute mastitis/abscess & 10 & 10.0 \\
\hline Inflammatory granulomatous mastitis & 4 & 4.0 \\
\hline Inflammatory fat necrosis & 2 & 2.0 \\
\hline Inflammatory tubercular mastitis & 6 & 6.0 \\
\hline Malignant- ductal & 10 & 10.0 \\
\hline Malignant- mucinous & 2 & 2.0 \\
\hline No definite opinion & 2 & 2.0 \\
\hline Suspicious for benign/ atypical & 3 & 3.0 \\
\hline Total & $\mathbf{1 0 0}$ & $\mathbf{1 0 0 . 0}$ \\
\hline Table 2. Spectrum of various Breast Lesions \\
\hline \multicolumn{2}{|l}{} \\
\hline \multicolumn{2}{|c|}{}
\end{tabular}

Benign fibroadenoma was most commonly seen (in 31 patients) followed by benign epithelial hyperplasia (17 patients), inflammatory acute mastitis (10 patients), malignant- ductal (10 cases), benign fibrocystic lesion (9 cases).

\begin{tabular}{|c|c|c|}
\hline Cytological 5 Tier Grading System & Frequency & Percent \\
\hline C1 & 2 & 2.0 \\
\hline C2 & 65 & 65.0 \\
\hline C3 4 & 18 & 18.0 \\
\hline C 5 & 3 & 3.0 \\
\hline \multicolumn{2}{|c|}{ Table 3. Categorisation of Breast Lesion on the } \\
basis of Five Tier System \\
\hline
\end{tabular}

Categorisation of breast lesion on the basis of 5 tier system was done in which 2 cases were of $\mathrm{C} 1,65$ cases of $\mathrm{C} 2$, 18 cases of $\mathrm{C} 3,3$ cases of $\mathrm{C} 4$ and 12 cases of $\mathrm{C} 5$.

\begin{tabular}{|c|c|c|}
\hline Benign & Frequency & Percent (\%) \\
\hline Epithelial hyperplasia & 17 & 27.87 \\
\hline Fibroadenoma & 31 & 50.82 \\
\hline Fibrocystic lesion & 9 & 14.75 \\
\hline Gynaecomastia & 4 & 6.56 \\
\hline Total & 61 & 100.0 \\
\hline hlo 4 Cyto & $\begin{array}{l}\text { yical Feat } \\
\text { Lesion }\end{array}$ & ign Breast \\
\hline
\end{tabular}

Fibroadenoma is the commonest condition in the benign category followed by benign epithelial hyperplasia.

\begin{tabular}{|c|c|c|}
\hline Inflammatory & Frequency & Percent (\%) \\
\hline Acute mastitis/ abscess & 10 & 45.45 \\
\hline Granulomatous mastitis & 4 & 18.18 \\
\hline Fat necrosis & 2 & 9.09 \\
\hline Tubercular mastitis & 6 & 27.27 \\
\hline Total & $\mathbf{2 2}$ & $\mathbf{1 0 0 . 0}$ \\
\hline Table 5. Cytomorphological Features of Inflammatory \\
Breast Lesion \\
\hline
\end{tabular}

Acute mastitis/ abscess is most common in inflammatory category followed by tubercular mastitis.

\begin{tabular}{|c|c|c|}
\hline Malignant & Frequency & Percent (\%) \\
\hline Ductal & 10 & 83.33 \\
\hline Mucinous & 2 & 16.67 \\
\hline Total & $\mathbf{1 2}$ & $\mathbf{1 0 0 . 0}$ \\
\hline \multicolumn{2}{|c|}{ Table 6. Cytomorphological Features of Malignant Breast } \\
Lesion
\end{tabular}




\begin{tabular}{|c|c|c|c|c|c|c|c|}
\hline & \multicolumn{4}{|c|}{ Age Group (in Years) } & \multirow{2}{*}{ Total } & \multirow{2}{*}{\begin{tabular}{|c|} 
Chi- \\
Square \\
Value \\
\end{tabular}} & \multirow[b]{2}{*}{$\begin{array}{c}\mathbf{P} \\
\text { Value }\end{array}$} \\
\hline $\begin{array}{l}\text { Type of } \\
\text { Lesions }\end{array}$ & $0-20$ & $21-4 c$ & $041-60$ & $>60$ & & & \\
\hline Benign & 16 & 36 & 9 & 0 & 61 & \multirow{6}{*}{32.59} & \multirow{6}{*}{0.001} \\
\hline Inflammatory & 2 & 17 & 3 & 0 & 22 & & \\
\hline Malignant & 0 & 3 & 8 & 1 & 12 & & \\
\hline $\begin{array}{l}\text { No definite } \\
\text { opinion }\end{array}$ & 0 & 2 & 0 & 0 & 2 & & \\
\hline $\begin{array}{c}\text { Suspicious } \\
\text { for benign/ } \\
\text { atypical }\end{array}$ & 1 & 2 & 0 & 0 & 3 & & \\
\hline Total & 19 & 60 & 20 & 1 & 100 & & \\
\hline \multicolumn{8}{|c|}{ Table 7. Association of Age with Breast Lesions } \\
\hline
\end{tabular}

Statistically significant association is seen between age and breast lesions ( $\mathrm{p}$ value less than 0.05 ).

\begin{tabular}{|c|c|c|c|c|c|c|}
\hline \multirow[b]{2}{*}{$\begin{array}{l}\text { Type of } \\
\text { Lesions }\end{array}$} & \multicolumn{3}{|c|}{ Site } & \multirow[b]{2}{*}{ Total } & \multirow{2}{*}{\begin{tabular}{|c|} 
Chi- \\
Square \\
Value \\
\end{tabular}} & \multirow[b]{2}{*}{$\begin{array}{c}\mathbf{P} \\
\text { Value }\end{array}$} \\
\hline & \begin{tabular}{|c|} 
Bilateral \\
Breasts \\
\end{tabular} & \begin{tabular}{|c|} 
Left \\
Breast
\end{tabular} & \begin{tabular}{|c|} 
Right \\
Breast
\end{tabular} & & & \\
\hline Benign & 3 & 36 & 22 & 61 & & \\
\hline Inflammatory & 0 & 7 & 15 & 22 & & \\
\hline Malignant & 0 & 2 & 10 & 12 & & \\
\hline $\begin{array}{c}\text { No definite } \\
\text { opinion }\end{array}$ & 0 & 2 & 0 & 2 & & \\
\hline $\begin{array}{l}\text { Suspicious } \\
\text { for benign/ } \\
\text { atypical }\end{array}$ & 0 & 0 & 3 & 3 & 18.81 & 0.016 \\
\hline Total & 3 & 47 & 50 & 100 & & \\
\hline
\end{tabular}

Here, $\mathrm{p}<.05$ statistically significant association was found between type of lesions vs. site.

\section{DISCUSSION}

The primary goal of FNA is to separate benign and malignant lesions, so that early diagnosis helps in management and reduces morbidity and mortality. Breast diseases are more common in women because oestrogen cyclically stimulates breast during their reproductive life. 11

The most common affected age group was 21 to 40 years, having $60 \%$ patients followed by 41 to 60 years having $20 \%$ patients. Similar age groups were observed by Chandanwale et $\mathrm{al}^{12}$ Likhar et al,13 Farkhanda et al and Godwins E et al.14 Haque et al ${ }^{15}$ have reported 30 - 40 years' age group as the most common age group in their study.

In our study, majority $55 \%$ of the patients with benign breast disease were in the age group of $21-40$ and these findings are consistent with those of similar studies from Karki et al,16 Guray et al,17 Houssami et al,18 Dahri et al and Naveen et al. ${ }^{19}$

FNAC results were divided according to the spectrum of lesions on cytomorphological interpretation and diagnosis into benign (61 cases), inflammatory (22 cases) and malignant (12 cases), atypical/ probably benign ( 3 cases) and no definite opinion ( 2 cases). In our study, benign lesions were maximum. They were 7 times more common than malignant lesions. Kumar et $\mathrm{al}^{20}$ also reported the same. Adesunkanmi et al 21 have reported $87.2 \%$ of benign lesions and Chandanwale et al ${ }^{12}$ have reported $80 \%$ of benign lesions.

The most common lesion in this study was fibroadenoma constituting $31 \%$ of the total cases. In the present study maximum cases of fibroadenoma were in the age group of 21-
30 years, which is similar to results shown by Kochhar et al,22 Khanzada et al,23 Iyer et al, ${ }^{24}$ Akhator et al, ${ }^{25}$ Irabor et al ${ }^{26}$ and Naveen et al. ${ }^{19}$

The number of malignant lesions in the present study were found to be twelve, which is in concordance with Park et $a l,{ }^{27}$ Rocha et $\mathrm{al}^{28}$ and Domínguez et al. ${ }^{29}$ Maximum number of malignant cases were found in 41 to 60 years of age group, which is similar to the results by Khan et al. In the 12 malignant lesions, maximum cases that is 10 cases were of ductal carcinoma and only 2 were diagnosed as mucinous carcinoma. Singh et $\mathrm{al}^{30}$ reported that ductal carcinoma is the most common breast malignancy and was found in the age group of 41 - 60 years. The present study showed similar results. Mayun et al 31 reported $40 \%$ cases of malignancy in their study. In our study, malignancy was found to be less as we cater rural population. Mortality and incidence is relatively lower in developing countries and other parts of globe in comparison to western population. Khan et $\mathrm{al}^{32}$ and Yeole et $\mathrm{al}^{33}$ in an epidemiological study compared the breast cancer incidence of various countries and found that incidence rates were very high in developed countries. The incidence of breast cancer increases with age, more common in urban population and in women of higher socioeconomic group. They also suggested that apart from genetic causes, change in lifestyle is responsible for increase in incidence of malignant breast lesions.

\section{CONCLUSION}

FNAC is a relatively simple procedure with good patient acceptance and low morbidity. It is an accurate, safe and repeatable procedure in the diagnosis of various breast lesions- both malignant and non-malignant. Our study showed benign breast lesions are commoner than malignant lesions. Fibroadenoma is the commonest condition in the benign category followed by benign epithelial hyperplasia, whereas ductal carcinoma accounts for the highest number of malignant lesions.

The most common affected age group was 21 to 40 years having $60 \%$ patients. FNAC results were divided according to the spectrum of lesions on cytomorphological interpretation and diagnosis into benign ( 61 cases), inflammatory ( 22 cases) and malignant (12 cases), atypical/ probably benign ( 3 cases) and no definite opinion ( 2 cases). In 12 malignant lesions, maximum cases that is 10 cases were of ductal carcinoma and only 2 were diagnosed as mucinous carcinoma. There is statistically significant association seen between age and breast lesions and also between site and breast lesions. Categorisation of breast lesion on the basis of 5 tier system was done in which 2 cases were of $\mathrm{C} 1,65$ cases of $\mathrm{C} 2,18$ cases of C3, 3 cases of $\mathrm{C} 4$ and 12 cases of $\mathrm{C} 5$.

\section{REFERENCES}

[1] Abhijit MG, Anantharaman D, Sumanth B, et al. Benign breast diseases: experience at a teaching hospital in rural India. Int J Res Med Sci 2013;1(2):73-8.

[2] Jarwani PB, Patel DC, Patel SM, et al. FNAC in a palpable breast lump. GCSMC J Med Sci 2013;2(2):1216.

[3] Koss L. Diagnostic cytology. $4^{\text {th }}$ edn. Philadelphia: Lippincott Williams \& Wilkins 1992: p. 6-11. 
[4] Place R, Velanovich V, Carter P. Fine needle aspiration in the clinical management of mammary masses. Surg Gynecol Obstet 1993;177(1):7-11.

[5] Dennison G, Anand R, Makar SH, et al. A prospective study of the use of fine needle aspiration cytology and core biopsy in the diagnosis of breast cancer. The Breast Journal 2003;9(6):491-3.

[6] Muddegowda PH, Lingegowda JB, Kurpad R, et al. The value of systematic pattern analysis in FNAC of breast lesions: 225 cases with cytohistological correlation. J Cytol 2011;28(1):13-9.

[7] Khan A, Jamali R, Jan M, et al. Correlation of FNAC and histopathology diagnosis in the evaluation of breast lumps. Int J Med Students 2014;2(2):40-3.

[8] Berner A, Sauer T. Fine-needle aspiration cytology of the breast. Ultrastruct Pathol 2011;35(4):162-7.

[9] Gerhard R, Schmitt FC. Liquid-based cytology in fine needle aspiration of breast lesions: a review. Acta Cytol 2014;58(6):533-42.

[10] Yusuf I, Atanda AT. Validity of FNAC of the palpable breast lesions: a teaching hospital experience. Nigerian Journal of Basic and Clinical Sciences 2014;11(1):36-40.

[11] Farkhanda JD, Muhammad SA, Ahsan AL, et al. An early diagnosis of benign breast diseases. Journal of Surgery Pakistan 2010;15(4):186-9.

[12] Chandanwale SS, Gupta K, Dharwadkar AA, et al. Pattern of palpable breast lesions on fi ne needle aspiration: a retrospective analysis of 902 cases. J Midlife Health 2014;5(4):186-91.

[13] Likhar KS, Fatima A, Hazari RA, et al. Diagnostic role of FNAC in breast lesions. IJRRMS 2013;3(1):12-4.

[14] Godwins E, David D, Akeem J. Histopathologic analysis of benign breast diseases in Makurdi, North Central Nigeria. International Journal of Medicine and Medical Sciences 2011;3(5):125-8.

[15] Haque A, Tyagi SA, Khan MH, et al. Breast lesions: a clinicohistopathological study of 200 cases of breast lump. JAMA 1980;150:1810-4.

[16] Karki OB, Kunwar D, De A. Benign breast diseases: profile at a teaching hospital. Am J Public Health Res 2015;3(4A):83-6.

[17] Guray M, Sahin AA. Benign breast diseases: classification, diagnosis and management. The Oncologist 2006;11(5):435-49.

[18] Houssami N, Cheung MN, Dixon JM. Fibroadenoma of the breast. Med J Aust 2001;174(4):185-8.

[19] Naveen N, Mukherjee A, Mahajan V. A clinical study of benign breast disease in rural population. J Evol Med Dent Sci 2013;2(30):5499-511.
[20] Kumar M, Ray K, Harode S, et al. The pattern of benign breast diseases in rural hospital in India. East and Central African Journal of Surgery 2010;15(2):59-64.

[21] Adesunkanmi AR, Agbakwuru EA. Benign breast disease at Wesley Guild Hospital, Ilesha, Nigeria. West Afr J Med 2001;20(2):146-51.

[22] Kochhar AK, Jindal U, Singh K. Spectrum of cytological findings in fine needle aspiration cytology of breast lumps with histopathology correlation: experience in a tertiary care rural hospital in India. Asian Pac J Cancer Prev 2013;14(12):7257-60.

[23] Khanzada TW, Samad A, Sushel C. Spectrum of benign breast diseases. Pak J Med Sci 2009;25(2):265-8.

[24] Iyer SP. Epidemiology of benign breast diseases in females of childbearing age group. Bombay Hosp J 2000;42:10.

[25] Akhator A. Benign breast masses in Nigeria. Nig J Surg Sci 2007;17(2):105-8.

[26] Irabor D0, Okolo CA. An audit of 149 consecutive breast biopsies in Ibadan, Nigeria. Pak J Med Sci 2008;24(2):257-62.

[27] Park IA, Ham EK. Fine needle aspiration cytology of palpable breast lesions. Histologic subtype in false negative cases. Acta Cytol 1997;41(4):1131-8.

[28] Rocha PD, Nadkarni NS, Menezes S. Fine needle aspiration biopsy of breast lesions and histopathologic correlation. Acta Cytol 1997;41(3):705-12.

[29] Domínguez F, Riera JR, Tojo S, et al. Fine needle aspiration of breast masses. An analysis of 1,398 patients in a community hospital. Acta Cytol 1997;41(2):341-7.

[30] Singh A, Haritwal A, Murali B. Pattern of breast lumps and diagnostic accuracy of fine needle aspiration cytology: a hospital based study from Pondicherry, India. The Internet Journal of Pathology 2010;11(2):16.

[31] Mayun AA, Pindiga UH, Babayo UD. Pattern of histopathological diagnosis of breast lesions in Gombe, Nigeria. Niger J Med 2008;17(2):159-62.

[32] Khan S, Kapoor AK, Khan IU, et al. Prospective study of pattern of breast diseases at Nepalgunj Medical College (NGMC), Nepal. Kathmandu Univ Med J (KUMJ) 2003;1(2):95-100.

[33] Yeole BB, Kurkure AP. An epidemiological assessment of increasing incidence and trends in breast cancer in Mumbai and other sites in India, during the last two decades. Asian Pacific Journal of Cancer Prevention 2003;4(1):51-6. 